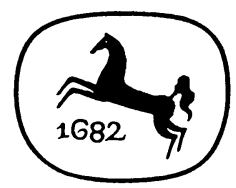

SPIEL DER MÄCHTE 
PAUL HANKAMER

\title{
SPIEL DER MÄCHTE
}

EIN KAPITEL

\author{
AUS GOETHES LEBEN
}

UND

GOETHES WELT

MCMLX

J. B. Metzlersche Verlagsbuchhandlung

Stuttgart 
MARTHA UND WILHELM WORRINGER 
Was auci als Wabrbeit oder Fabel

In tausend Büchern dir erscheint,

Das alles ist ein Turm $q^{u}$ Babel,

Wenn es die Liebe nicht vereint.

Die Jabre nabmen dir, du sagst, so vieles:

Die eigentliche Lust des Sinnespieles,

Erinnerung des allerliebsten Tandes

Von gestern, weit und breiten Landes

Durchscbweifen frommt nicht mebr; selbst nicht von oben

Der Ebren anerkannte Zier, das Loben,

Erfreulich sonst. Aus eignem Tun Bebagen

Quillt nicht mebr auf, dir feblt ein dreistes Wagen!

Nun wüßt' ich nicht, was dir Besondres bliebe?

Mir bleibt genug! Es bleibt Idee und Liebe!

ZAHMR XENIEN

Scbon im kinde leiden,

Das an den wall gebt, sicb zum brunnen bückt,

Im jüngling qual und unrast, qual im manne

Und webmut, die er binter läcbeln barg. 